\title{
An LCA-based evaluation of biomass to transportation fuel production and utilization pathways in a large port's context
}

\author{
Georgios Archimidis Tsalidis ${ }^{1}$ - Fadhila El Discha $^{1} \cdot$ Gijsbert Korevaar $^{2}$ • \\ Wim Haije ${ }^{1} \cdot$ Wiebren de Jong ${ }^{1,4} \cdot$ Jaap Kiel $^{1,3}$
}

Received: 3 April 2017/Accepted: 10 July 2017/Published online: 15 July 2017

(c) The Author(s) 2017. This article is an open access publication

\begin{abstract}
This study evaluates whether a transition of large ports facilities to biofuel production for mobility improves the environmental performance and satisfies the renewable energy directive (RED) and it is the first LCA study that considers biofuel production from torrefied wood. The systems studied are wood, torrefied wood, and straw pellets circulating fluidized bed gasification for $\mathrm{H}_{2}$, synthetic natural gas, or Fischer-Tropsch (FT) diesel production and use. These systems are evaluated for their global warming, acidification, eutrophication and particulate matter potentials, as well as, for their aggregated environmental performance. The effects of the electricity mix selection and ecoinvent database's economic allocation are also analyzed. All biomass systems result in a better aggregated environmental performance and benefits for the global warming potential. However, regarding the acidification, particulate matter, and eutrophication potentials, most
\end{abstract}

Electronic supplementary material The online version of this article (doi:10.1007/s40095-017-0242-8) contains supplementary material, which is available to authorized users.

Georgios Archimidis Tsalidis

g.a.tsalidis@tudelft.nl

1 Process and Energy Laboratory, Delft University of Technology, Leeghwaterstraat 39, 2628 CA Delft, The Netherlands

2 Engineering Systems and Services Department, Delft University of Technology, Jaffalaan 5, 2628 BX Delft, The Netherlands

3 Energy research Centre of the Netherlands (ECN), P.O. Box 1, 1755 ZG Petten, The Netherlands

4 Faculty of Mathematics and Natural Sciences, Chemical Technology, Engineering and Technology Institute of Groningen, Nijenborgh 4, 9747 AG Groningen, The Netherlands biomass systems are inferior to the reference systems. Switching to a zero-emission electricity mix offers benefits for all the biomass and fossil- $\mathrm{H}_{2}$ systems and researchers should use databases cautiously. The bio- $\mathrm{H}_{2}$ and FT diesel of wood-based systems show the best environmental performance and satisfy the current and future RED targets. On one hand, the bio- $\mathrm{H}_{2}$ systems result in the largest benefits regarding the global warming potential, and on the other hand, both wood-based FT diesel systems offer overall benefits which concern not only the sustainable target of $\mathrm{CO}_{2}$ emissions reduction, but also the air quality improvement of the broader area as well.

Keywords Life cycle assessment - Torrefaction . Gasification · Transportation fuel $\cdot$ Wood $\cdot$ Straw

\section{Introduction}

The current harbours do not consist only of marine facilities. Especially, the large harbours worldwide consist of industrial infrastructure, such as oil refineries, chemical production clusters, and power plants. The port of Rotterdam (PoR) is the largest European port and the fifth worldwide. The PoR is guided by the Port Vision 2030, which states that the share of sustainable energy in the port's energy mix will increase from 10 to $30 \%$ in 2030 and a $60 \%$ reduction of the $\mathrm{CO}_{2}$ emission of the 1990 levels (24 Mton $\mathrm{CO}_{2}$ eq.) is targeted. In 2030, Rotterdam aims to have a syngas cluster based on biomass, coal, and oil residuals [1]. Thus, the port authorities envisage that, by then, Rotterdam will still be the most important European port and industrial complex, with a strong combination of the Global and Europe's Industrial Cluster [2]. The challenge faced by the port authorities for sustainable development 
requires activities that meet the current and future needs of the enterprise and its stakeholders whilst protecting the human and natural resources well-being. Since the current port's infrastructure consists, for a large part, of industry for automotive fuels and gas production, a potential alternative green business activity would be the production of bio-syngas which will be converted to liquid or gaseous transportation fuels for use in the conventional vehicles and fuel cell (FC) cars. This green alternative must be part of the Port Vision 2030, comply with the Renewable Energy Directive (RED) 2009/28/EC targets and reduce serious threats over human health, as the IEA warned that air pollution will kill millions if environmental policies do not change [3]. The Renewable Energy Directive (RED) 2009/28/EC [4] concerns the greenhouse gas (GHG) emissions during the life cycle of a transportation biofuel and does not address other environmental impacts. With regard to the GHG emissions, the construction of relevant infrastructure and vehicles is yet to be considered in the RED 2009/28/EC. The directive's GHG emission savings target is $35 \%$ until 2017 and it rises to $50 \%$ by 2017 . However, in 2018 , the target rises again to $60 \%$, but only for new production plants.

Biomass has been recognized as a sustainable energy source. However, its untreated form is not ideally suited for energy conversion applications. This is due to its generally high moisture content, which corresponds to a low energy content per $\mathrm{kg}$. This makes the conversion of biomass complicated and logistics more expensive. As a result, efforts are being made to develop upgrading processes that convert biomass into a fuel with improved properties with respect to logistics and end-use.

Gasification is a thermochemical technology that converts a (typically) solid fuel into a gas that is rich in $\mathrm{CO}$, $\mathrm{H}_{2}, \mathrm{CO}_{2}$, and $\mathrm{H}_{2} \mathrm{O}$. Gasification, and especially the fluidized bed reactor type, is attractive due to the large variety of feedstock that can be employed and the wide variety of the end-uses of the produced gas. The latter can be converted into liquid fuels, gaseous fuels, and chemicals or it can also be directly combusted in a furnace for heat and/or power generation.

Torrefaction is considered the least severe thermochemical processing of biomass. It is used to upgrade the biomass to a solid biofuel at a typical temperature range between 230 and $300{ }^{\circ} \mathrm{C}$, in an oxygen-deficient atmosphere. Its main product is comparable to low-grade coal, with improved properties compared to the untreated biomass, such as higher carbon and energy density, enhanced grind ability and reduced susceptibility to microbial degradation. Therefore, torrefied biomass has been suggested as suitable feedstock for co-firing with coal, gasification, and thermochemical fuel production [5-7]. Specifically for the gasification of torrefied wood, our group has shown that the coupling of torrefaction with circulating fluidized bed gasification resulted in benefits regarding syngas quality $\left(\mathrm{H}_{2}\right.$ and $\left.\mathrm{CO}\right)$ and tar reduction [33].

Life cycle assessment (LCA) is a tool which since 1992 [8] has been continuously getting more attention as it evaluates the environmental performance of products, services, and systems, and identifies opportunities for improvement. Therefore, LCA is already considered a powerful tool regarding the environmental aspect of sustainable development. There have been a number of LCA and well-to wheel studies regarding the generation of liquid and gaseous biofuels via wood gasification. However, so far, only two studies [9, 10] used empirical data; and none of them has considered torrefied wood as the gasifier's feedstock. In general, the LCA practitioners construct their life cycle (LC) inventory based on literature data and do not include the construction of the relevant infrastructure (including road infrastructure) in their system boundaries. In addition, they do not consider the effects of biomass storage, even though the supply chain of biomass typically contains a storage period. Sunde et al. [11] conducted a review regarding the environmental impacts of wood-toliquid fuels production and use, and reported a GHG emissions range between 129 and $200 \mathrm{~g} \mathrm{CO}_{2} \mathrm{eq} \mathrm{km}^{-1}$. This range of values resulted due to differences in methodology chosen, such as the exclusion of various stages from the life cycle boundaries and allocation methods. They concluded that liquid biofuels derived from woody biomass do offer an environmentally sound and viable solution to the transport sector. The up-to-date relevant literature showed that LCA practitioners use mostly literature sources [12-18] for their foreground data, typically limit their environmental impacts to global warming potential (GWP) and acidification potential (AP), use dedicated plantations or forestry residues as the origin of their selected feedstock, and do not pelletize their considered feedstock. In general, concerning GWP wood is superior to fossil fuels and the studies based on literature foreground data result in greater environmental benefits than studies [9] with empirical data, except from the Joint Research Centre (JRC) [10] study. However, in that study, there is no transparency regarding the setup of the considered biomass system, as the researchers did not present a detailed inventory. On the other hand, wood does not provide environmental benefits regarding AP and eutrophication potential (EP) due to the fertilizer use. Table 1 presents an overview of the relevant studies.

Based on previous LCA studies, wood appears to be a promising feedstock for gasification-derived transportation fuels. In addition, LCA practitioners so far have constructed their LC inventories mainly by combining different literature sources and databases which reduces the 
Table 1 Overview of relevant environmental studies

\begin{tabular}{|c|c|c|c|c|c|c|c|}
\hline References & $\begin{array}{l}\text { Transportation } \\
\text { biofuel }\end{array}$ & Feedstock & Impacts & $\begin{array}{l}\mathrm{GWP}\left(\mathrm{g} \mathrm{CO}_{2}\right. \\
\left.\text { eq km }{ }^{-1}\right)\end{array}$ & $\begin{array}{l}\mathrm{AP}\left(\mathrm{g} \mathrm{SO}_{2}\right. \\
\text { eq km }\end{array}$ & $\begin{array}{l}\text { Foreground } \\
\text { data }\end{array}$ & Assumptions \\
\hline [9] & $\mathrm{SNG}^{\mathrm{j}}$ & $\begin{array}{l}\text { Sawmill } \\
\text { residues }\end{array}$ & GHG & 202 & - & Empirical & $\begin{array}{l}\text { Zero upstream } \\
\text { emissions }\end{array}$ \\
\hline [10] & FT diesel & Wood & GHG & 16 & - & n.d. & n.d. \\
\hline [12] & $\begin{array}{l}\mathrm{H}_{2}, \mathrm{SNG}, \mathrm{FT} \\
\text { diesel }\end{array}$ & Poplar wood & GWP, AP & $58-132$ & $0.37-0.68$ & Literature & Exergy allocation \\
\hline [13] & FT diesel & $\mathrm{SRC}^{\mathrm{k}}$ wood & $\begin{array}{l}\text { GWP, AP, EP, } \\
\text { POCP }^{\mathrm{a}}\end{array}$ & 200 & 0.36 & Literature & Exergy allocation \\
\hline [14] & SNG & $\begin{array}{l}\text { Forest } \\
\text { residues }\end{array}$ & GWP & $32-40$ & - & Literature & $\begin{array}{l}\text { No by-products } \\
\text { considered or used }\end{array}$ \\
\hline [15] & $\mathrm{H}_{2}$ & Poplar wood & $\begin{array}{l}\text { GWP, AP, EP, } \\
\text { ODP }^{\mathrm{b}}, \mathrm{POFP}^{\mathrm{c}}\end{array}$ & $385^{\mathrm{h}}$ & $0.02^{\mathrm{i}}$ & $\begin{array}{l}\text { Aspen } \\
\text { Plus }^{\mathrm{TM}}\end{array}$ & Fertilizer use \\
\hline [16] & FT diesel & Willow & GWP, $\mathrm{AEP}^{\mathrm{d}}$ & $68^{\mathrm{g}}$ & - & Literature & $\begin{array}{l}\text { Different energy } \\
\text { scenarios }\end{array}$ \\
\hline [17] & $\mathrm{H}_{2}$ & Wood & ReciPe $2008^{f}$ & 130 & 1.0 & Literature & Various \\
\hline [18] & FT diesel & $\begin{array}{l}\mathrm{SRC}^{\mathrm{k}} \text { wood } \\
\text { and straw }\end{array}$ & Eco-indicator $99^{\mathrm{g}}$ & $100-130$ & - & Literature & Heavy use of fertilizer \\
\hline
\end{tabular}

${ }^{a}$ Photooxidant creation potential

b Ozone depletion potential

c Photochemical oxidation

d Aquatic eutrophication potential

e $\mathrm{g} \mathrm{CO}_{2}$ eq $\mathrm{MJ}^{-1}$

${ }^{\mathrm{f}}$ Method which includes climate change potential, terrestrial acidification potential, freshwater eutrophication potential, particulate matter formation potential, photochemical oxidant formation potential, human toxicity potential, terrestrial eco-toxicity potential, and freshwater ecotoxicity potential

g Includes climate change potential, acidification potential, eutrophication potential, ozone depletion potential, and particulate matter formation potential

${ }^{\mathrm{h}}$ In $\mathrm{g} \mathrm{CO}_{2}$ eq $\mathrm{kg}^{-1} \mathrm{H}_{2}$

i $\mathrm{g} \mathrm{SO}_{2}$ eq kg ${ }^{-1} \mathrm{H}_{2}$

${ }^{\mathrm{j}} \mathrm{SNG}$ stand for substitute natural gas

${ }^{k}$ SRC stands for short rotation coppice

applicability of their results. For example, the use of the ecoinvent database results in incorporating the economic allocation, or LCA practitioners use different types of allocations or just exclude relevant by-products and the biomass storage stage from their LC boundaries. In addition, to the best of our knowledge, there is no LCA study regarding the environmental performance of transportation biofuels derived from torrefied wood which considers the RED emissions targets. Therefore, the goal of this study is to evaluate the overall environmental performance of three transportation biofuels production pathways when a circulating fluidized bed gasifier is considered to generate the syngas which is upgraded and used in a FC car and EURO 5 cars. The hot spots of the related environmental performances will be identified. To improve the applicability of this study, empirical data are used, and the RED target limits and particulate matter potential (PMP) are considered. Therefore, empirical data for the LC stages, such as torrefaction of wood and its subsequent gasification, are used and system expansion is used instead of allocation when it is possible. Apart from the specific environmental impacts, such as the GWP, AP, PMP, and EP, the aggregated environmental performance is evaluated as well. In addition, the improvement of the carbon footprint of the electricity mix and the type of allocation of the ecoinvent database are evaluated. Finally, the results of this study are expected to be applicable to other ports with relevant infrastructure as the PoR.

\section{Methodology}

The CMLCA software [19] and the CML 2001 and Traci impact models were used to acquire assessment results regarding the GWP, EP, AP, and PMP. All these impacts have been weighted to calculate the aggregated 
environmental impact based on the Building for Environmental and Economic Sustainability (BEES) stakeholder panel [20] method. Due to the fact that not all environmental impacts that are included in this method have been considered by this study, the weighting factors were recalculated proportionally. The weighting factors of the impacts that are included in the BEES method and are considered in our study have been increased proportionally based on the impacts that are included in the BEES method, but are not considered in our study; a table with the weighting factors is presented in supplementary material section.

\section{Goal and scope definition}

The goal of this LCA study is to assess the environmental impacts related to the production and utilization of transportation biofuels derived from product gas upgrading when torrefied wood pellets, wood pellets, and straw pellets are used as feedstock. The produced transportation biofuels were compared with their fossil alternatives. The foreground data used in this study are collected from in-house performed gasification experiments, and part of these data is provided by a Dutch torrefaction company or modelled using Aspen Plus ${ }^{\mathrm{TM}}$, a commercial flowsheeting package. Furthermore, the background data are collected from the ecoinvent database.

Finally, two sensitivity analyses were performed regarding the influence of the allocation type of the ecoinvent database and the electricity mix. The former concerns the effect of using ecoinvent database in LCA energy studies and the latter concerns the effect of a transition to a more sustainable electricity mix as used in Switzerland. Detailed information concerning the sensitivity analyses can be found in the supplementary material section.

\section{Functional unit}

The main function of all systems is the production of transportation fuels and their utilization in vehicles. Therefore, the selected functional unit is $1 \mathrm{~km}$ distance travelled by a vehicle.

\section{System boundaries}

The boundaries of the biomass, petroleum oil, and natural gas systems are all cradle-to-grave (Fig. 1). Materials and energy consumed regarding the construction and demolition of relevant infrastructure were out of the scope of this study, except from the road infrastructure. It has been shown that the contribution of constructing and demolishing a power plant is insignificant with respect to the fuel conversion and utilization stages [21].

\section{Allocation}

Allocation was avoided whenever possible and system expansion was preferred. However, the ecoinvent database is constructed based on the economic allocation, and therefore, using economic allocation could not be avoided for processes inserted from the database.

\section{Study assumptions}

In this paper, we focused on forestry residues produced in The Netherlands, Belgium, and Germany and wheat straw produced in the western part of The Netherlands. Both biomass kinds were pretreated in The Netherlands, gasified, and converted to transportation biofuels in the South-Holland region. Therefore, the gasification plant was decided to be located in the South-Holland region and a capacity of $20 \mathrm{MW}_{\text {th }}$, was chosen, which is of the same order but somewhat smaller than the $84 \mathrm{MW}_{\text {th }} \mathrm{RWE} /$ Essent Amer waste-wood-based circulating fluidized bed gasifier situated in The Netherlands. The gasification data used are derived from the pilot scale gasifier in the Technical University of Delft. These data were not scaled up, only autothermal gasifier operation is assumed, as expected on industrial level. On industrial level, only the carbon conversion efficiency will be higher than measured during the experiments on which the data were based. The wood/straw pellet plant had a production capacity of $70 \mathrm{ktons} \mathrm{a}^{-1}$ [22] and the torrefied wood pellets plant had a production capacity of $35 \mathrm{ktons} \mathrm{a}^{-1}$ [23]. Both pretreatment plants were decided to be located at realistic distances (being $100 \mathrm{~km}$ ) from the production sites of biomass due to associated benefits in logistics, especially for torrefaction. Due to the fact that it was impossible to find relevant industrial data for the biofuel conversion processes, such as the FT process, the Aspen Plus ${ }^{\mathrm{TM}}$ flowsheeting software was used with input from relevant literature. Finally, even though there are a few refuelling stations for $\mathrm{H}_{2}$ (one station) and CNG (two stations) in the broader Rotterdam area, it was decided to assume the distance between the gasification plant and the gas station to be the same for all biomass systems (being $15 \mathrm{~km}$ ).

\section{Impact categories}

All the considered systems were biomass-based energy conversion systems and the PoR focuses on the GHG emissions and the air quality, and the global warming (for 100 years), acidification, and particulate matter impact categories were selected as they contribute to the air 


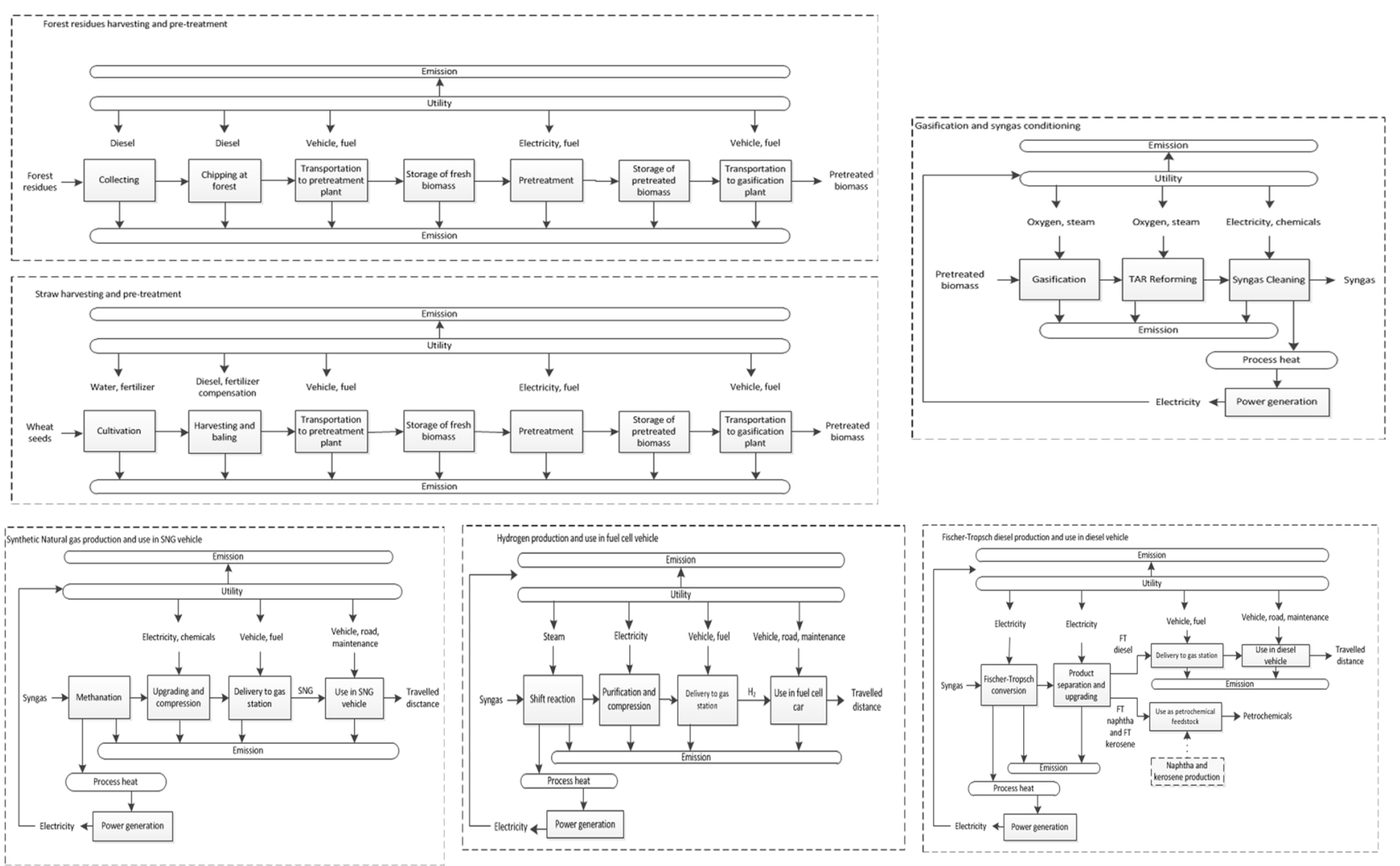

Fig. 1 LCA system boundaries

pollution. In addition, acidification and eutrophication impacts were also selected as they are affected by transport and energy conversion systems.

\section{Life cycle inventory}

The life cycle inventory with all the inputs and outputs of the life cycle stages is presented in Table A1 in supplementary material section.

\section{Harvesting of biomass and chips or bales production}

The first LC stage of each analyzed biomass system was the harvest of the wood or the production and collection of wheat straw. The wood was considered to be derived from an established forest or a natural forest was managed sustainably. For both biomass feedstocks, approximately 1 year was assumed to be required for regrowing the biomass to sequester the initial $\mathrm{CO}_{2}$ pulse emitted [24].

The wood was harvested, forwarded, and chipped on site. Similarly, the straw was produced, collected, and baled at the farm. The fuel consumption and emissions produced during harvesting, forwarding, and chip/bale production depended on the equipment used. In this paper, consumption data regarding the equipment used for forest residues were retrieved from literature. The forwarder and chipper equipment had a productivity of approximately 360 ton day ${ }^{-1}$ [25]. In addition, the data for the straw equipment were acquired from the ecoinvent database [26].

\section{Transportation}

The inland transportation was assumed to take place with lorries which follow the Euro 5 emission standards. The wood chips or straw bales were transported over a distance of $100 \mathrm{~km}$, from the production site to the pretreatment plant, then the produced solid biofuel was transported over a distance of $200 \mathrm{~km}$ to the gasification plant, and the produced transportation biofuel was transported over a distance of $15 \mathrm{~km}$ to the gas station. Data for the transportation stages were collected from the ecoinvent database.

\section{Production of pellets}

The wood chips and straw bales arrived at the pretreatment plants and they were stored for one week before and after processing; emissions during the storage period were based on literature sources [27-30]. The feedstocks were processed at the torrefaction plant which was equipped with a pellet mill or at the pelletization plant. In this way, the untreated feedstocks became more uniform and easier to 
handle. Therefore, two kinds of wood fuels, torrefied wood pellets, Torrcoal black (TB) and wood pellets, Torrcoal white (TW), and one kind of straw pellets were considered. Only for the TW and TB systems, wood chips and propane were used as fuel for drying purposes, respectively. The composition and lower heating value (LHV) of the feedstocks used are presented in Table 2. Data regarding torrefaction followed by pelletization were collected from a supplier company, Torrcoal [23]. On the other hand, the data concerning pelletization of untreated wood and straw were collected from the literature $[31,32]$.

\section{Gasification and gas cleaning}

The pretreated feedstocks arrived at the gasifier site, where they were converted to product gas. The product gas was conditioned to be upgraded to syngas quality and used for further processing. Data for the biomass gasification process were retrieved from experiments performed using a steam-oxygen $100 \mathrm{~kW}_{\text {th }}$ circulating fluidized bed gasifier operating in a steady state, at $850{ }^{\circ} \mathrm{C}$ and atmospheric pressure at the Delft University of Technology [34, 33]. The selected process conditions were beneficial due to the increased cold gas efficiency and carbon conversion efficiency. In addition, at such temperature agglomeration issues could be reduced during straw gasification. Due to the process conditions selected, the gasification was considered autothermal. Gas conditioning was essential as impurities, such as particles and tarry compounds, are present in the raw product gas and needed to be removed. The particles were removed with cyclones and a non-catalytic filter operating at $450{ }^{\circ} \mathrm{C}$. In addition, a fixed bed reactor was considered downstream the gasifier, where oxygen and steam are supplied to convert the tarry compounds via catalytic autothermal reforming reactions at $850{ }^{\circ} \mathrm{C}$ and atmospheric pressure. The steam feed rate was varied to adjust the syngas $\mathrm{H}_{2}$ and $\mathrm{CO}$ ratio according to the requirement of the final transportation fuel conversion process. Subsequently, an amine absorber and a stripper were used to remove the $\mathrm{CO}_{2}$ from the clean syngas. These cleaning and conditioning processes were modelled using the Aspen Plus ${ }^{\mathrm{TM}}$ software.

\section{Biofuel conversion}

The syngas was converted into three kinds of transportation biofuels: $\mathrm{H}_{2}$, SNG, and FT diesel. Syngas was converted to $\mathrm{H}_{2}$ by the water-gas shift reaction, purified with PSA, and compressed to a pressure of 350 bar [35]. The by-product of the shift reaction was biogenic $\mathrm{CO}_{2}$. The electricity needed in this process was generated from combusting a part of the biomass feedstock of the gasifier. For SNG production, methanation performance was based on the experiments by the Energy research Center of The Netherlands (ECN) [36]. It consisted of a two-step methanation reactor configuration, the first reactor operated at $350{ }^{\circ} \mathrm{C}$ and the second reactor operated at $200{ }^{\circ} \mathrm{C}$ to shift the exothermal reaction equilibrium towards the product side. In addition, upgrading was performed by drying using a triethylene glycol (TEG) absorber and $\mathrm{CO}_{2}$ removal with an amine absorber. The FT biodiesel production occured at $245{ }^{\circ} \mathrm{C}$ and 25 bar [37]. The by-products of this process, $\mathrm{C}_{1}$ - to $\mathrm{C}_{4}$ hydrocarbons, $\mathrm{H}_{2}$ and naphtha, were recycled or combusted for power generation. The main product $\left(\mathrm{C}_{5+}\right.$ hydrocarbons) is refined to FT biodiesel. During refining, kerosene and naphtha are produced; both by-products are considered via system expansion.

\section{Fossil fuels supply chains}

Data from the fossil fuels supply chains were collected from the ecoinvent database v2.2 [26]. The data used were
Table 2 Composition and lower heating values of biofuels (on an "as received" mass basis)

\begin{tabular}{lccl}
\hline & Torrcoal white $(\mathrm{TW})^{\mathrm{a}}$ & ${\text { Torrcoal black }(\mathrm{TB})^{\mathrm{a}}}^{\mathrm{a}}$ & Wheat straw $^{\mathrm{b}}$ \\
\hline Moisture & 5.9 & 4.1 & 6.8 \\
Ash & 1.0 & 2.1 & 11.7 \\
Carbon & 46.6 & 53.5 & 40.7 \\
Hydrogen & 5.8 & 5.2 & 5.5 \\
Nitrogen & 0.2 & 0.5 & 0.6 \\
Sulphur & 0.8 & 0.7 & 0.1 \\
Oxygen & 39.7 & 33.9 & 41 \\
Lower heating value & 17.6 & 20.1 & 14 \\
\hline
\end{tabular}

\footnotetext{
a From [33]

b From [34]

c The fuel lower calorific values have been determined by following the method provided by Phyllis database, using the Milne's empirical formula, in $\mathrm{MJ} / \mathrm{kg}$
} 
specifically for petroleum oil and natural gas produced, refined, and used in The Netherlands. Only for the fossil- $\mathrm{H}_{2}$ system, the steam-reforming process of natural gas did not exist in the ecoinvent database. Therefore, it was modelled using Aspen Plus ${ }^{\mathrm{TM}}$.

\section{Use of biofuels and fossil fuels in vehicles}

Finally, the transportation biofuels and fossil fuels were used in passenger vehicles: the bio- $\mathrm{H}_{2}$ and the fossil- $\mathrm{H}_{2}$ in a FC car, the FT diesel and the fossil diesel in a Euro 5 diesel car, and the SNG and the natural gas in a Euro 5 car. Data regarding these stages were used from ecoinvent database and from international literature.
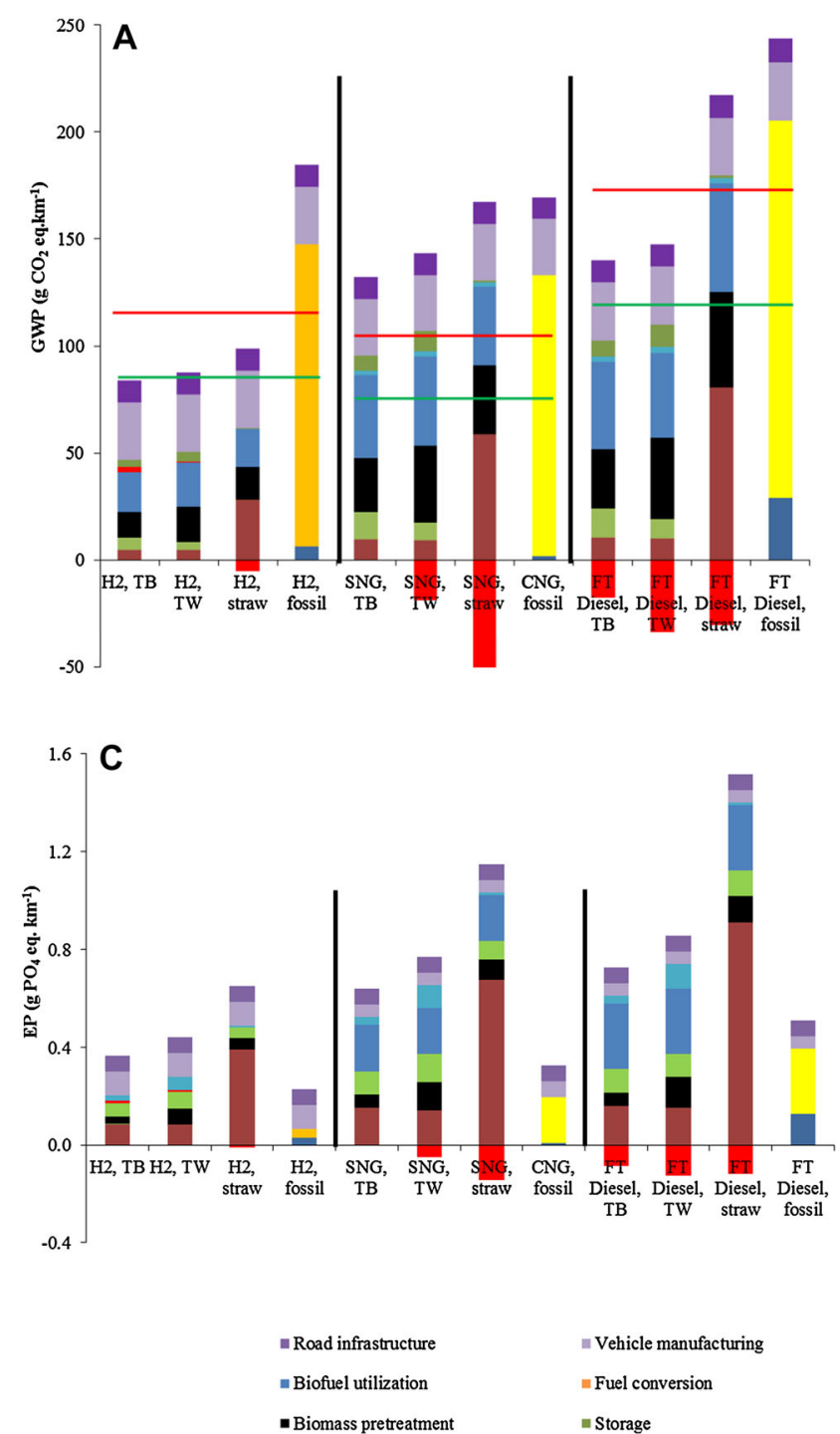

\section{Results and discussion}

\section{Global warming potential}

The GWP results and the GHG reduction target based on the RED 2009/28/EC criteria are presented in Fig. 2a. In Fig. 3, the average results of this study, with standard deviations values, are compared with other studies' results. Among the biomass systems, the bio- $\mathrm{H}_{2}$ systems result in the lowest GWP due to the biofuel utilization stage, which is the most significant contributor. This stage improves significantly the system's specific fuel consumption (Table 3), which concerns the amount of energy in the raw biomass that is needed to cover a distance of $1 \mathrm{~km}$. Among the biomass systems, the wood-based systems show the best performance and the GWP benefits can be up to 54 and
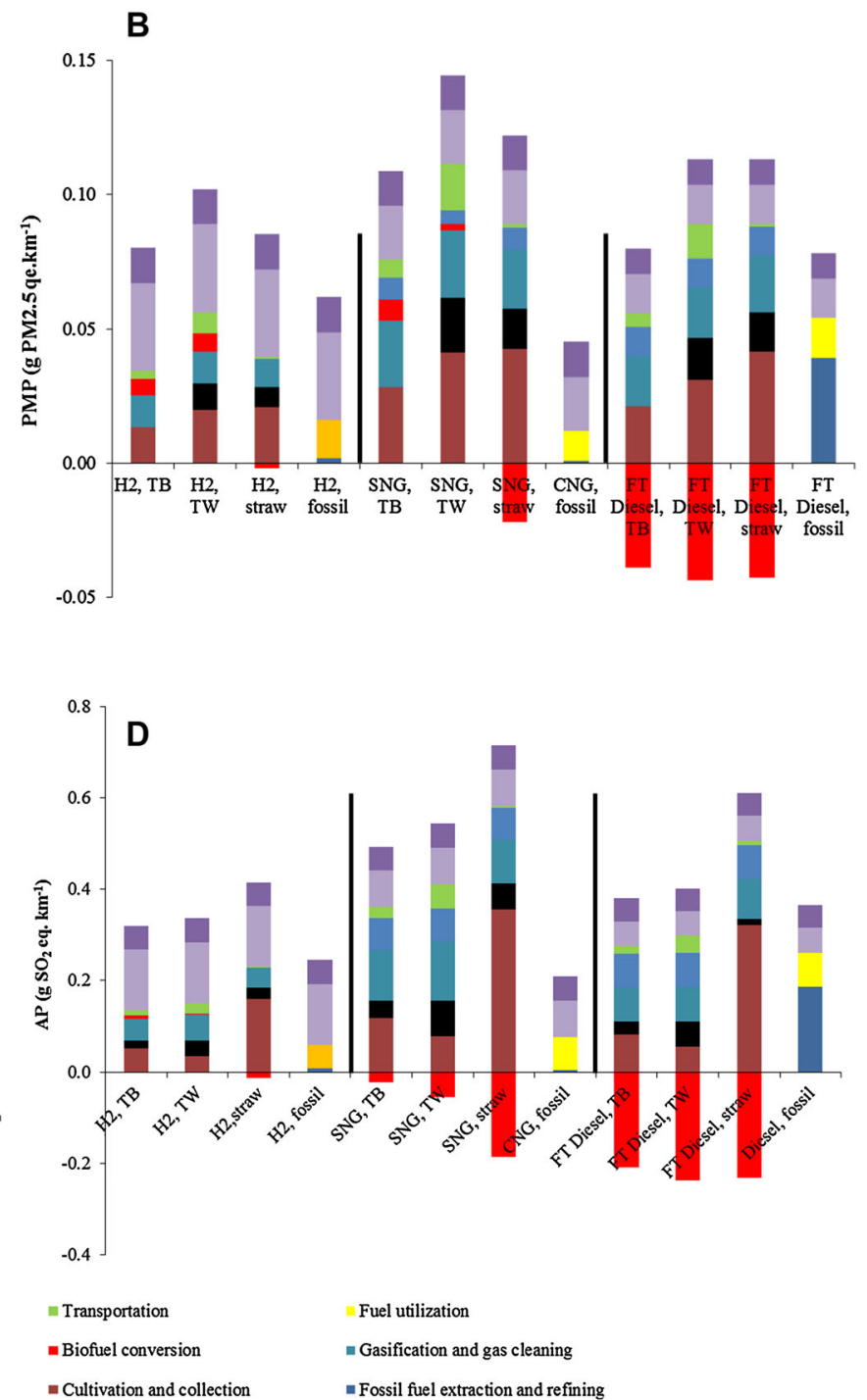

Fig. 2 Environmental impact results. a GWP results and targeted emissions reduction based on the RED 2009/28/EC (the red and green horizontal lines concern the savings targets until 2016 and by 2017), b PMP results, c EP results, and d AP results 
$52 \%$ for $\mathrm{H}_{2}$ and FT diesel, respectively. Regarding the straw-based systems, the SNG system results in the largest benefits, approximately $40 \%$.

The gasification and gas cleaning, biomass pretreatment, and road infrastructure stages contribute significantly to the GWP results for all systems, whereas the cultivation stage is a large contributor for the straw-based systems. In most biomass systems, negative emissions are produced during the biofuel conversion stage as the excess electricity is exported to the grid. Specifically for the FT diesel conversion stage, the production of naphtha and kerosene results in additional benefits. However, these benefits are smaller than the excess electricity benefits. In general, between the TB- and TW-based systems, torrefaction results in benefits in the pretreatment stage, due to decreasing the electricity requirements of the pelletization step, and in the transportation stage due to the feedstock having a higher calorific value. Hence, fewer feedstock (in mass unit) should be transported to produce the same amount of transportation fuel (in energy unit) in the torrefied system. Moreover, torrefaction results in benefits in the gasification and gas cleaning stage by lowering the requirements for the gas cleaning step due to the lower tar content of the product gas. On the other hand, due to the mass and energy losses during torrefaction, more wood chips are required for the TB-based systems, which result in higher storage emissions of the wood chips.

If the road infrastructure and vehicle production stages are excluded from the system boundaries, the $\mathrm{CO}_{2}$ emission reduction can be recalculated based on the RED 2009/28/EC criteria. In such a case, all biomass systems satisfy the RED target of the $35 \%$ reduction. The bio- $\mathrm{H}_{2}$ systems result in a reduction range between 61 and $68 \%$, the SNG systems result in a reduction range between 28 and $54 \%$, and the FT diesel systems result in a reduction range between 27 and 63\%. However, if the target of 2017 is to be achieved, then only the bio- $\mathrm{H}_{2}$ systems, the strawbased SNG system and both the TW and the TB FT diesel systems fulfil the target. Finally, if the reduction concerns a new production plant, then the bio- $\mathrm{H}_{2}$ systems and the TW FT diesel systems satisfy the $60 \%$ savings target.

For bio- $\mathrm{H}_{2}$ production and use, all three biomass systems result in significant benefits. Among them, TB results in the lowest GWP. This difference can mainly be attributed to the lower electricity requirements for the pretreatment stage of the TB-based system compared to the other two systems and due to the quality of the gas produced at the gasification plant which requires less intensive upgrading than TW- or straw-based systems. Nevertheless, in both wood systems, larger emissions during the storage stage exist, which can be reduced, even to zero, if the biomass management is optimized and specialized equipment is used, e.g. limited storage time and indoor storage. Our GWP results are in agreement with Weinberg and Kaltschmitt [12] who reported a value of $132 \mathrm{~g} \mathrm{CO}_{2}$ eq $\mathrm{km}^{-1}$ and Singh et al. [17] who reported $130 \mathrm{~g} \mathrm{CO}_{2}$ eq $\mathrm{km}^{-1}$. Both authors have omitted various stages which are considered in this study, such as storage of biomass, which can contribute up to $7 \%$ of the GWP. On the other hand, Susmozas et al. [15] and Wulf and Kaltschmitt [38] reported much lower values of 4.5 and $22 \mathrm{~g} \mathrm{CO}_{2}$ eq $\mathrm{km}^{-1}$ (when converted with the fuel economy factor of this study; initial value of $30 \mathrm{~g} \mathrm{CO}_{2}$ eq $\mathrm{MJ}^{-1} \mathrm{H}_{2}$ ), respectively. However, in both cases the system boundaries were limited up to the production of hydrogen.

Regarding the compressed SNG systems, the strawbased system results in the best environmental performance. The three biomass systems are comparable with respect to biomass pretreatment and gasification and gas cleaning stages. However, this difference in the GWP of the straw-based system derives mainly from negative emissions due to the excess electricity produced in the biofuel conversion stage, due to the high steam content of the product gas. The cultivation stage of the straw-based system contributes significantly to its GWP, but not to an extent that offsets the benefits of excess electricity
Fig. 3 Comparison of the GWP results of this study with relevant literature

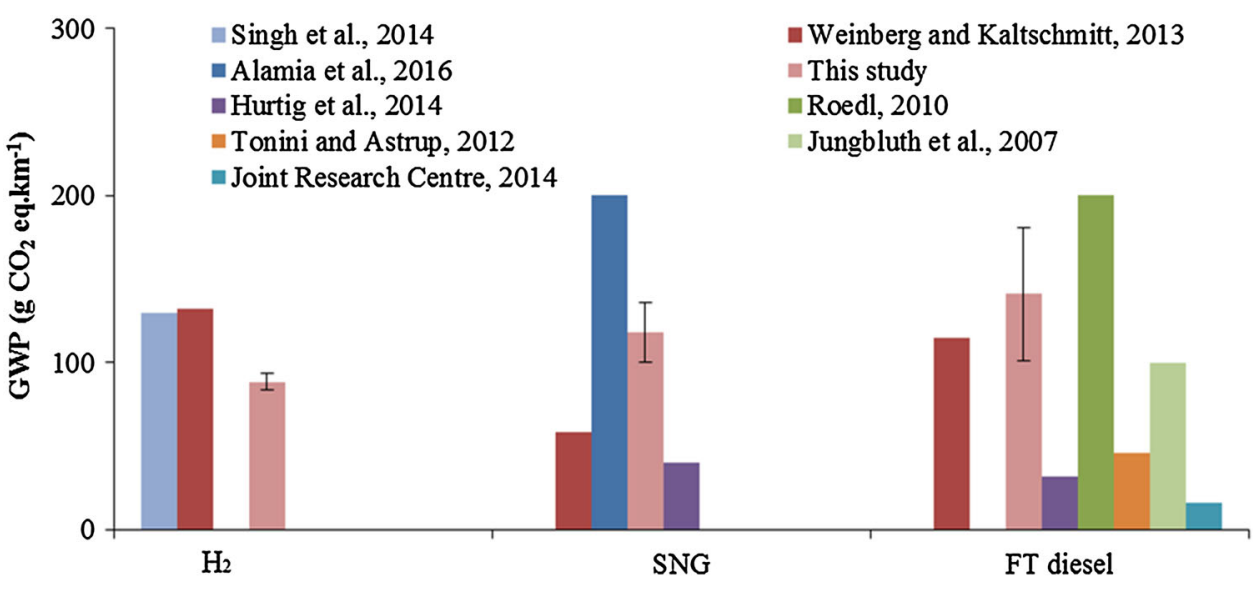


Table 3 Specific fuel consumption (untreated biomass-to-fuel utilization)

\begin{tabular}{|c|c|c|c|c|c|c|c|c|c|}
\hline & $\mathrm{H}_{2}, \mathrm{~TB}$ & $\mathrm{H}_{2}, \mathrm{TW}$ & $\mathrm{H}_{2}$, straw & SNG, TB & SNG, TW & SNG, straw & FT diesel, TB & FT diesel, TW & FT diesel, straw \\
\hline$\eta^{\mathrm{a}}$ & 3.8 & 3.7 & 2.9 & 8.7 & 8.1 & 6.4 & 9.0 & 8.7 & 8.6 \\
\hline
\end{tabular}

${ }^{a}$ In $\mathrm{MJ} / \mathrm{km}$, the calculation is based on the LHV of the feedstock

generation. Our GWP results are partially in agreement with Alamia et al. [9] who reported a value of $200 \mathrm{~g} \mathrm{CO}_{2}$ eq $\mathrm{km}^{-1}$. These authors modelled the GoBiGas demonstration plant; hence, they assumed larger transportation distances and they considered compressed SNG with a lower LHV (approximately 10\%) than this study. On the other hand, Hurtig et al. [14] reported a much lower GWP value of $40 \mathrm{~g} \mathrm{CO}_{2} \mathrm{eq} \mathrm{km}^{-1}$. However, these authors do not explain what gasifier type they considered which makes any comparison difficult, but they did consider a commuter car; which is different from the car used in this study based on the fuel consumption rates, $0.4 \mathrm{kWh} \mathrm{km}^{-1}$ instead of $0.6 \mathrm{kWh} \mathrm{km}^{-1}$ (in ecoinvent database).

Regarding the FT biodiesel systems, the TW-based system results in the lowest GWP; marginally better than the TB-based system and significantly better than the straw-based system. This difference can be attributed to the biofuel conversion stage of the TB-based system and due to the cultivation stage of straw-based system. The former results in less excess electricity, whereas the latter contributes highly. The electricity requirements for stages such as pretreatment (pelletization process) and gasification $\left(\mathrm{O}_{2}\right.$ input) and gas cleaning contribute to this lower GWP values of both TW- and TB-based systems compared to the straw-based systems. These results are in agreement with Weinberg and Kaltschmitt [12], Wang et al. [39], Jungbluth et al. [18], and Roedl [13]. However, Roedl [13] reported a higher GWP of $200 \mathrm{~g} \mathrm{CO}_{2} \mathrm{eq} \mathrm{pkm}^{-1}$ when SRC wood was used as feedstock. Due to the nature of the plantation, the author did consider herbicides, site preparation processes, etc. These processes contribute to $80 \%$ of his final result, so a larger GWP value is expected, which is the same as for the straw-based system in our study. On the other hand, Hurtig et al. [14] reported a much lower result of $31 \mathrm{~g} \mathrm{CO}_{2}$ eq $\mathrm{pkm}^{-1}$. This difference can be explained with the stages that are included in the system boundaries of their study and with the fact that their FT process' selectivity of diesel is approximately $80 \%$ of the FT raw products which is much higher than the selectivity data used for our study. Similarly, JRC [10] reported very low GHG emissions when wood-derived FT diesel is produced. JRC reported approximately $16 \mathrm{~g} \mathrm{CO}_{2}$ eq $\mathrm{pkm}^{-1}$. The results of JRC are due to their oversimplified wood system, where wood is not pretreated but gasified and upgraded as it is. Therefore, the wood supply system in that report is completely different from the wood supply systems considered in our study, as biomass is not stored, nor pretreated upstream the gasification stage. In addition, the manufacture of the vehicle or road infrastructure is not considered by the JRC. Finally, only Tonini and Astrup [16] reported very small environmental benefits when FT diesel replaces fossil diesel, due to the cultivation stage of the energy crop that they considered.

\section{Particulate matter potential}

The PMP results are presented in Fig. 2b. The different nature of transportation fuels means that higher PMP values are expected in the fossil diesel system, rather than in fossil $\mathrm{H}_{2}$ and NG systems. As a result, the PMP result of the fossil diesel is approximately two times the value of the other two reference systems. Benefits are achieved only when FT diesel is produced. The reduction in PM potential is 48,11 , and $8 \%$ for TB pellets, TW pellets, and straw pellets, respectively. In general, the conversion stage of the FT systems, i.e., the excess electricity and by-products, has a positive effect. The much better PMP of TB-based FT diesel system is due to the torrefaction pretreatment. Torrefaction strongly enhances energy densification which results in benefits in the transportation stages. Furthermore, due to the decreased electricity requirements in the pelletization step, additional benefits are achieved in the TBbased FT diesel system. Finally, concerning the SNG and bio- $\mathrm{H}_{2}$ systems, the increase in the PMP is so large due to biomass cultivation and collection, gasification and gas cleaning, as well as biofuel conversion stages. The former two result in requirements on diesel and electricity, whereas the latter does not result in by-products that offer benefits, except for the straw-based SNG system.

\section{Eutrophication potential}

The biomass systems do not offer any EP benefits compared to the fossil systems. Among the fossil systems, the fossil diesel system shows the highest EP (see Fig. 2c). Among the biomass systems, the adverse effects range from 127 to $343 \%$; the lowest potential is achieved with the TB-based FT diesel system, whereas the highest results from the straw-based SNG system. For wood-based systems, the collection and chipping of wood in the forest and 
the biofuel utilization are the largest contributors due to the $\mathrm{NO}_{x}$ emissions from diesel fuel used for the equipment and the Euro 5 car operation. On the other hand, the use of fertilizers and pesticides contribute more than $50 \%$ of the straw-based systems result.

\section{Acidification potential}

Figure $2 \mathrm{~d}$ presents the AP values of each system. The fossil- $\mathrm{H}_{2}$ and NG systems result in a much lower AP than the fossil diesel system. In general, apart from the TW- and TB-based FT diesel systems, the other biomass systems result in no benefits. Especially, regarding the straw-based systems, the cultivation and collection stage is the main contributor, as it contributes up to $80 \%$ of the total emissions due to the pesticides used. The benefits in the AP for the TW- and TB-based FT diesel systems can mainly be attributed to the by-product yield of the biofuel conversion stage; replacing fossil naphtha and fossil kerosene affects the results, as these fossil fuels are high in sulphur content. Wood-based systems for the production of $\mathrm{H}_{2}$ and SNG do not show benefits when compared with the fossil systems due to the power consumption during pretreatment and gasification stages which are supplied from the Dutch grid that is high on fossil resources. The results of this paper are in agreement with Roedl [13] concerning the FT diesel systems. On the other hand, they are partially in contradiction with Susmozas et al. [15] and Weinberg and Kaltschmitt [12]. These authors did conclude that methane utilization is more beneficial than hydrogen and FT diesel. However, the former authors attributed the worse performance to the cultivation stage of poplar, whereas the latter reported deviating results from this study due to the inclusion of the vehicle manufacturing stage, which contributes significantly to their results, but they omitted the road infrastructure stage. Finally, our results are in contradiction with Singh et al. [17]. These authors reported that their high AP emission result emanates from battery and motor requirements during the production stage, as well as the production of platinum which is used as the catalyst in fuel cells. In total, these stages contribute up to $70 \%$ of the total impact result.

\section{Aggregated environmental results based on BEES stakeholder panels method}

The aggregated environmental impact results, based on the BEES stakeholder panel method, are presented in Fig. 4. It was found that even though there are no environmental benefits in specific environmental impact categories for certain biomass systems (Fig. 2), each aggregated biomass system performance results in benefits compared to its reference system. This is attributed to the larger weighting factor that the GWP has than the other potentials. In general, the total environmental performance can be improved from $20 \%$ (SNG case of TB and TW) to even $55 \%\left(\mathrm{H}_{2}\right.$ of $\mathrm{TB}$ and FT diesel of $\mathrm{TW}$ ) compared to the reference systems.

\section{Sensitivity analysis}

\section{Economic versus mass allocation}

The difference between economic and mass allocations of straw production is presented in Fig. 5 as in our case straw is not used as fodder, but for energy applications. The mass allocation factor is the mass ratio of grain to straw, which is 2:3. The environmental impact values, when mass allocation is used, are normalized with the previously calculated results for the straw-based systems. Based on the larger yield and lower financial value of wheat straw compared the grain, the allocation factors in the ecoinvent database were modified with a factor of three for all straw-based systems. The new straw results are expected to be worse regarding all impacts, especially EP, as it is mostly influenced by fertilizer usage of the cultivation and collection stage. The results show that the new results vary from 140 to $223 \%$ compared to the previously calculated results.

\section{Cleaner electricity mix, the Swiss case}

The second sensitivity analysis concerned the effect of the electricity mix on the environmental impacts. An electricity mix consisting of a larger share of zero-emission technologies was selected, that of Switzerland. In Fig. 6, the results of the sensitivity analysis are normalized with the previously calculated results. Changes are expected regarding all stages which consume mainly electricity, such as the pretreatment and the gasification and gas cleaning. Indeed, all systems are affected, showing a reduction of up to $55 \%$, except for the natural gas system and the fossil diesel system. Regarding the natural gas system, energy requirements for the extraction and refining of natural gas stage are achieved with the utilization of natural gas itself. Whereas concerning the fossil diesel system, refinery gas and heavy fuel oil are mainly used in the extraction and refining stage. The largest benefits are achieved in the GWP of FT diesel systems and straw-based SNG system.

\section{Conclusions and recommendations}

The aim of this study was to use empirical data to investigate whether increasing a port's capacity of biomass for the production of transportation fuels derived from syngas, with torrefied wood pellets, wood pellets, or straw pellets 
Fig. 4 Aggregated environmental impact points based on BEES stakeholders panels method

Fig. 5 Sensitivity analysis when mass allocation is used in the cultivation stage of strawbased systems (in ecoinvent database), normalized results
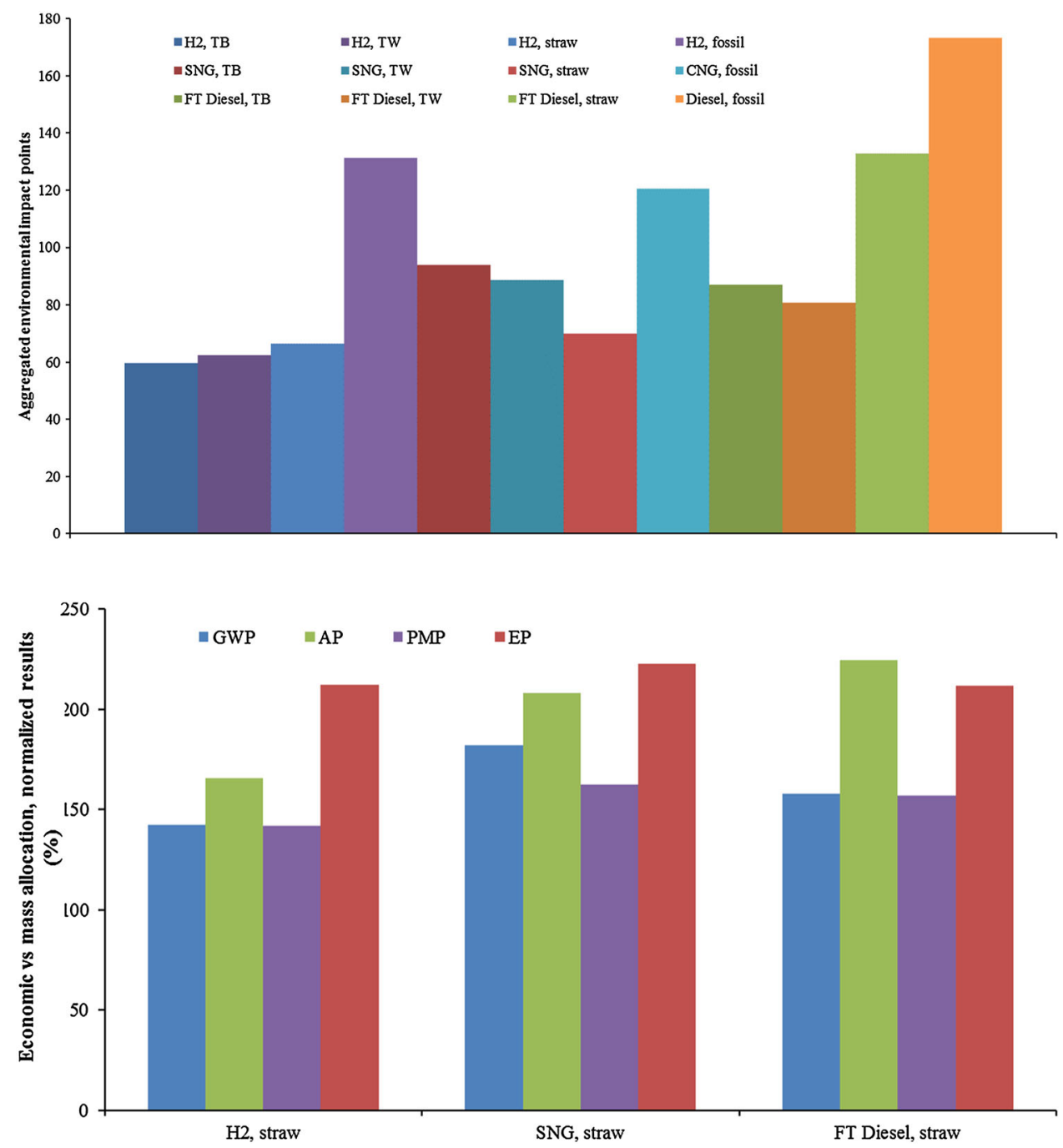

as feedstock, offers environmental benefits. In addition, our results should be applicable to other ports with similar infrastructure as the port of Rotterdam.

It is concluded that the transportation biofuels did not offer environmental benefits in every single impact category when they replaced fossil fuels. However, all biomass systems resulted in a better aggregated environmental performance than the fossil resource-based systems. Moreover, all biomass systems resulted in a substantial GWP reduction, from 45 to $78 \%$, and they comply with the RED 2009/28/EC. For 2017 only the bio- $\mathrm{H}_{2}$ systems, the straw-based SNG system and the TW- and TB-based FT diesel systems comply with the RED target. In case European countries have to comply with the even more stringent target of $60 \%$ emissions savings for new production plants, then all systems would be benefited if less fossil sources are used. The bio- $\mathrm{H}_{2}$ systems result in the largest benefits with respect to GWP, ranging between 84 and $93 \mathrm{~g} \mathrm{CO}_{2}$ eq $\mathrm{km}^{-1}$, whereas the TB- and TW-based FT diesel systems offer overall benefits which concern not only the Port Vision 2030 target of $\mathrm{CO}_{2}$ emissions reduction (122 and $114 \mathrm{~g} \mathrm{CO}_{2}$ eq $\mathrm{km}^{-1}$, respectively), but also the air quality improvement of the broader area as well (0.039 and $0.064 \mathrm{~g}$ PM $2.5 \mathrm{eq} \mathrm{km}^{-1}$, respectively). However, the biomass systems resulted in inferior performance regarding AP, EP, or PMP, except for TB- and TWbased FT diesel systems which showed benefits in the AP and PMP impact categories. In general, wood offers more environmental benefits than straw as feedstock due to the emissions associated with the cultivation and collection stage of straw, and wood torrefaction offers additional benefits in the transportation and in gasification and gas cleaning stages. The storage emissions of wood chips are contributing up to $11 \%$ of the GWP; thus, a proper management of the wood supply chain is highly recommended to even eliminate this contribution. Other contributors to environmental impacts are the pretreatment and gasification and gas cleaning stages, up to approximately $34 \%$ for both, of the biomass systems. Both stages can be further improved two- or threefold using electricity sources with a 


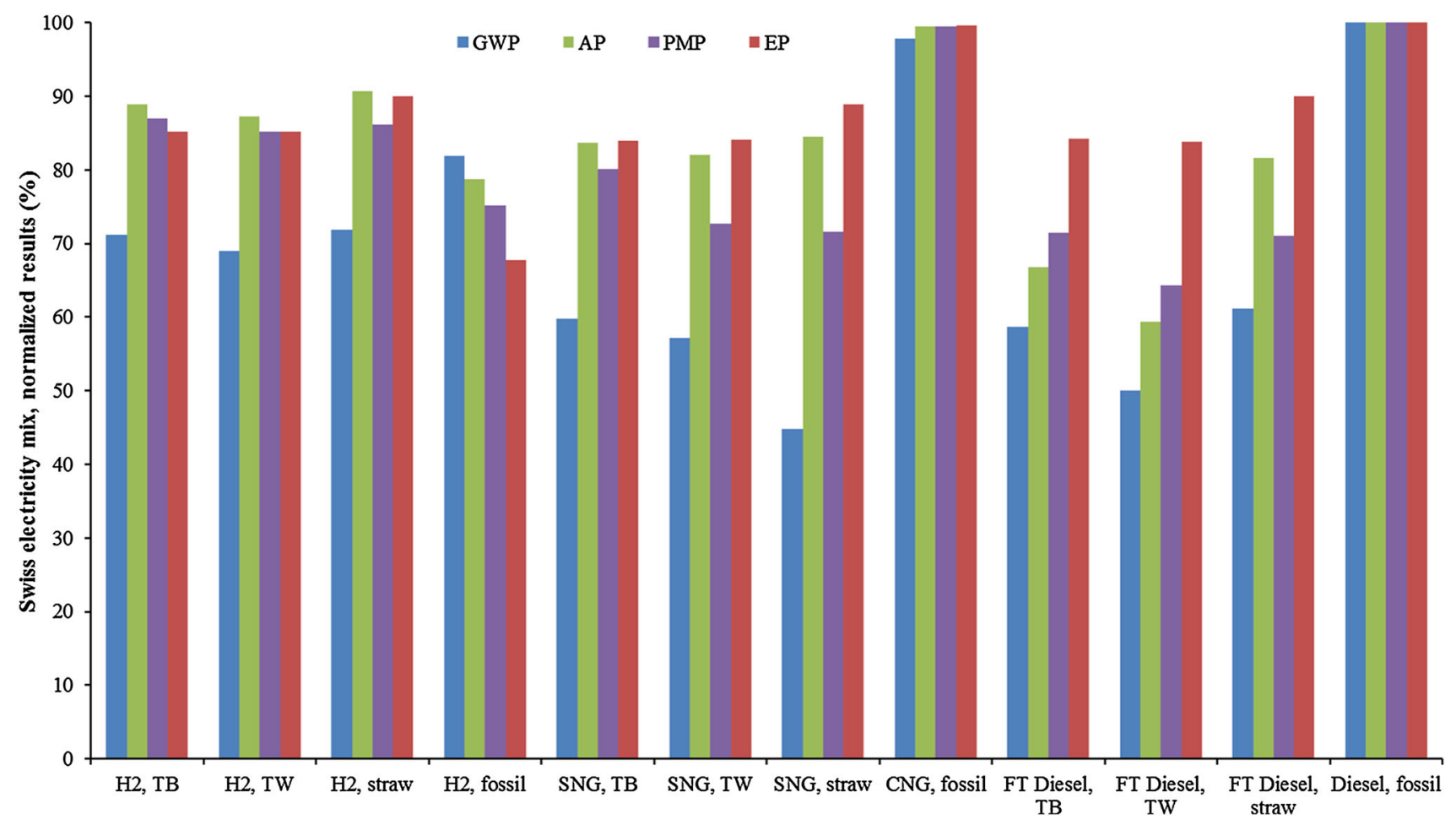

Fig. 6 Sensitivity analysis of electricity mix used (Swiss compared to Dutch), normalized results

lower carbon footprint. In addition, in this study, propane is consumed in the torrefaction plant for heat production. However, in the future, when the $\mathrm{CO}_{2}$ targets become more stringent, a torrefaction plant would reduce the fossil fuels utilization and use a renewable energy source for its heat requirements. Finally, the economic allocation (already) integrated in the ecoinvent database affects the final results and LCA practitioners should import data from databases with caution. Therefore, it is recommended that the port authorities investigate the economical aspect of utilizing torrefied wood pellets and wood pellets regarding such biomass to transportation fuel pathways.

Acknowledgements This work is part of the activities carried out in the framework of the FP7 (Infrastructures) European project "Biofuels Research Infrastructure for Sharing Knowledge (BRISK)"Project no. 284498, and of the Dutch National TKI project "INVENT Pretreatment", Project no. TKIBE01011, for investigation and improvement of torrefaction technologies. The authors would like to thank Dr. Manuela di Marcello who participated in the gasification experiments with untreated and torrefied wood pellets, Dr. Ir. Marcin Siedlecki who performed the gasification experiments with straw and allowed us to use his results in this study, and Torrcoal company which provided the data regarding the torrefaction process.

Open Access This article is distributed under the terms of the Creative Commons Attribution 4.0 International License (http://crea tivecommons.org/licenses/by/4.0/), which permits unrestricted use, distribution, and reproduction in any medium, provided you give appropriate credit to the original author(s) and the source, provide a link to the Creative Commons license, and indicate if changes were made.

\section{References}

1. PoR (Port of Rotterdam Authority): Port Vision 2030 (2011). https://www.portofrotterdam.com/sites/default/files/upload/PortVision/Port-Vision-2030.pdf. Accessed 10 Feb 2016

2. Hiranandani, V.: Sustainable development in seaports: a multicase study. WMU J. Marit. Aff. 13, 127-172 (2014). doi:10.1007/ s13437-013-0040-y

3. International Energy Agency: Energy and Air Pollution 2016World Energy Outlook Special Report (2016). http://www.iea. org/publications/freepublications/publication/WorldEnergyOutlook SpecialReport2016EnergyandAirPollution.pdf. Accessed $15 \mathrm{Feb}$ 2016

4. European Commission: DIRECTIVE 2009/28/EC OF THE EUROPEAN PARLIAMENT AND OF THE COUNCIL of 23 April 2009 on the promotion of the use of energy from renewable sources and amending and subsequently repealing Directives 2001/77/EC and 2003/30/EC. http://eur-lex.europa.eu/legal-con tent/EN/TXT/PDF/?uri=CELEX:32009L0028\&from=en, (2009). Accessed 15 Jan 2016

5. Ciolkosz, D., Wallace, R.: A review of torrefaction for bioenergy feedstock production. Biofuels Bioprod. Biorefining. 5, 317-329 (2011). doi:10.1002/bbb. 275

6. Bridgeman, T.G., Jones, J.M., Williams, A., Waldron, D.J.: An investigation of the grindability of two torrefied energy crops. Fuel 89, 3911-3918 (2010). doi:10.1016/j.fuel.2010.06.043

7. Bergman, P.C.A., Kiel, J.H.A., Veringa, H.J.: Combined torrefaction and pelletisation. The TOP process. ECN-C-05-073 (2005). https://www.ecn.nl/docs/library/report/2005/c05073.pdf. Accessed 11 Jan 2016

8. Heijungs R., Guinee J.B., Huppes G., Lankreijer R.M., Udo de Haes H.A., Wegener Sleeswijk A., Ansems A.M.M., Eggels P.G., van Duin R., de Goede H.P.: Environmental life cycle assessment of products, Leiden, The Netherlands (1992) 
9. Alamia, A., Magnusson, I., Johnsson, F., Thunman, H.: Well-towheel analysis of bio-methane via gasification, in heavy duty engines within the transport sector of the European Union. Appl. Energy 170, 445-454 (2016). doi:10.1016/j.apenergy.2016.02. 001

10. Joint Research Centre: WELL-TO-TANK Report Version 4.a (2014). https://iet.jrc.ec.europa.eu/about-jec/sites/iet.jrc.ec. europa.eu.about-jec/files/documents/report_2014/wtt_report_v4a. pdf. Accessed 12 Feb 2016

11. Sunde, K., Brekke, A., Solberg, B.: Environmental impacts and costs of woody Biomass-to-Liquid (BTL) production and use-a review. For. Policy Econ. 13, 591-602 (2011). doi:10.1016/j.for pol.2011.05.008

12. Weinberg, J., Kaltschmitt, M.: Life cycle assessment of mobility options using wood based fuels-comparison of selected environmental effects and costs. Bioresour. Technol. 150, 420-428 (2013). doi:10.1016/j.biortech.2013.08.093

13. Roedl, A.: Production and energetic utilization of wood from short rotation coppice-a life cycle assessment. Int. J. Life Cycle Assess. 15, 567-578 (2010). doi:10.1007/s11367-010-0195-0

14. Hurtig, O., Leible, L., Kälber, S., Kappler, G., Spicher, U.: Alternative fuels from forest residues for passenger cars-an assessment under German framework conditions. Energy Sustain. Soc. 4, 1 (2014). doi:10.1186/2192-0567-4-12

15. Susmozas, A., Iribarren, D., Dufour, J.: Life-cycle performance of indirect biomass gasification as a green alternative to steam methane reforming for hydrogen production. Int. J. Hydrog. Energy. 38, 9961-9972 (2013). doi:10.1016/j.ijhydene.2013.06. 012

16. Tonini, D., Astrup, T.: LCA of biomass-based energy systems: a case study for Denmark. Appl. Energy 99, 234-246 (2012). doi:10.1016/j.apenergy.2012.03.006

17. Singh, B., Guest, G., Bright, R.M., Strømman, A.H.: Life cycle assessment of electric and fuel cell vehicle transport based on forest biomass. J. Ind. Ecol. 18, 176-186 (2014). doi:10.1111/ jiec. 12098

18. Jungbluth, N., Büsser, S., Frischknecht, R., Tuchschmid, M.: Ökobilanz von Energieprodukten: Life cycle assessment of biomass-to-liquid fuels. Berne, $\mathrm{CH}$ (2008)

19. Heijungs, R.: CMLCA: scientific software for LCA (2009). http:// www.cmlca.eu. Accessed 10 Jan 2015

20. Lippiatt, B.C.: Evaluating sustainability using standard approaches: the BEES tool. In: Presented at the ASTM Special Technical Publication (2009)

21. Damen, K., Faaij, A.P.C.: A life cycle inventory of existing biomass import chains for "green" electricity production. Universiteit Utrecht, Copernicus Institute, Department of Science, Technology and Society], Utrecht (2003)

22. Junginger, M., Sikkema, R.: Development and promotion of a transparent European Pellets Market Creation of a European realtime Pellets Atlas. Pellet market country report NETHERLANDS. http://www.pelletsatlas.info/cms/site.aspx? $\mathrm{p}=9186$. Accessed 11 Jan 2016

23. Brouwers, J.J.M.: Torr-Coal Group (2015). http://task32.ieabioe nergy.com/wp-content/uploads/2017/03/Graz-Brouwers-2011.pdf. Accessed 12 Jul 2015

24. Cherubini, F., Peters, G.P., Berntsen, T., Strømman, A.H., Hertwich, E.: $\mathrm{CO} 2$ emissions from biomass combustion for bioenergy: atmospheric decay and contribution to global warming. GCB Bioenergy 3, 413-426 (2011). doi:10.1111/j.1757-1707. 2011.01102.x
25. Zhang, F., Johnson, D.M., Wang, J.: Life-cycle energy and GHG emissions of forest biomass harvest and transport for biofuel production in Michigan. Energies 8, 3258-3271 (2015). doi:10. 3390/en8043258

26. Frischknecht, R., Jungbluth, N., Althaus, H.-J., Doka, G., Dones, R., Heck, T., Hellweg, S., Hischier, R., Nemecek, T., Rebitzer, G., Spielmann, M.: The ecoinvent database: overview and methodological framework (7 pp). Int. J. Life Cycle Assess. 10, 3-9 (2005). doi:10.1065/lca2004.10.181.1

27. Wihersaari, M.: Evaluation of greenhouse gas emission risks from storage of wood residue. Biomass Bioenergy 28, 444-453 (2005). doi:10.1016/j.biombioe.2004.11.011

28. Tumuluru, J.S., Lim, C.J., Bi, X.T., Kuang, X., Melin, S., Yazdanpanah, F., Sokhansanj, S.: Analysis on storage off-gas emissions from woody, herbaceous, and torrefied biomass. Energies 8, 1745-1759 (2015). doi:10.3390/en8031745

29. Emery, I.R., Mosier, N.S.: The impact of dry matter loss during herbaceous biomass storage on net greenhouse gas emissions from biofuels production. Biomass Bioenergy 39, 237-246 (2012). doi:10.1016/j.biombioe.2012.01.004

30. Hess, J.R., Wright, C.T., Kenney, K.L.: Cellulosic biomass feedstocks and logistics for ethanol production. Biofuels Bioprod. Biorefining. 1, 181-190 (2007). doi:10.1002/bbb.26

31. Mani, S.: A systems analysis of biomass densification process (2005). https://circle.ubc.ca/handle/2429/17106. Accessed 10 Sep 2016

32. Li, X., Mupondwa, E., Panigrahi, S., Tabil, L., Adapa, P.: Life cycle assessment of densified wheat straw pellets in the Canadian Prairies. Int. J. Life Cycle Assess. 17, 420-431 (2012). doi:10. 1007/s11367-011-0374-7

33. Carbo, M.C., Bouwmeester, M.: INVENT/Pre-treatment Openbaar Eindrapport. Netherlands. ECN-E-16-038 (2016). https://www. ecn.nl/publications//PdfFetch.aspx?nr=ECN-E-16-038. Accessed 22 Jan 2017

34. Siedlecki, M., de Jong, W.: Biomass gasification as the first hot step in clean syngas production process - gas quality optimization and primary tar reduction measures in a $100 \mathrm{~kW}$ thermal input steam-oxygen blown CFB gasifier. Biomass Bioenergy 35, S40-S62 (2011). doi:10.1016/j.biombioe.2011.05.033

35. Baldwin, D.: Development of high pressure hydrogen storage tank for storage gaseous truck delivery (2013). https://www. hydrogen.energy.gov/pdfs/review13/pd021_baldwin_2013_o.pdf. Accessed 22 Jan 2016

36. Zwart, R.W.R., Boerrigter, H., Deurwaarder, E.P., van der Meijden, C.M., van Paasen, S.V.B.: Production of synthetic natural gas from biomass-development and operation of an integrated bio-SNG system. ECN-E-06-018, Petten, The Netherlands (2006)

37. Leckel, D.: Diesel production from Fischer-Tropsch: the past, the present, and new concepts. Energy Fuels 23, 2342-2358 (2009). doi:10.1021/ef900064c

38. Wulf, C., Kaltschmitt, M.: Life cycle assessment of biohydrogen production as a transportation fuel in Germany. Bioresour. Technol. 150, 466-475 (2013). doi:10.1016/j.biortech.2013.08. 127

39. Wang, B., Gebreslassie, B.H., You, F.: Sustainable design and synthesis of hydrocarbon biorefinery via gasification pathway: integrated life cycle assessment and technoeconomic analysis with multiobjective superstructure optimization. Comput. Chem. Eng. 52, 55-76 (2013). doi:10.1016/j.compchemeng.2012.12.008 